\title{
DMAT, an inhibitor of protein kinase CK2 induces reactive oxygen species and DNA double strand breaks
}

\author{
CAROLIN C. SCHNEIDER ${ }^{1}$, ANDREA HESSENAUER ${ }^{2}$, CLAUDIA GÖTZ $^{1}$ and MATHIAS MONTENARH ${ }^{1}$ \\ ${ }^{1}$ Medizinische Biochemie und Molekularbiologie, Universität des Saarlandes, 66424 Homburg; \\ ${ }^{2}$ Institut für Zoologie und Endokrinologie, M24, Universität Ulm, Albert Einstein Allee 11, 89069 Ulm, Germany
}

Received January 9, 2009; Accepted February 27, 2009

DOI: $10.3892 /$ or_00000392

\begin{abstract}
Elevated levels of protein kinase CK2 were found in tumour cells compared to normal cells. Thus, inhibition of CK2 kinase activity seems to be an attractive method to stop growth of cancer cells. Two drugs, namely tetrabromobenzotriazole, TBB, and 2-dimethylamino-4,5,6,7-tetrabromo1H-benzimidazole, DMAT were found to specifically inhibit CK2 and to induce apoptosis in tumour cells. The aim of the present study was the elucidation of the mode of action of these two inhibitors in addition to the inhibition of CK2 activity. The decrease in CK2 kinase activity induced by both inhibitors was accompanied by a reduction in cell viability and induction of apoptosis. Most interestingly, we detected that DMAT in contrast to TBB induced reactive oxygen species, ROS and DNA-double-strand-breaks (DSBs). Thus, in addition to inhibition of CK2 one has to consider ROS and DSBs contributing to the induction of apoptosis by DMAT.
\end{abstract}

\section{Introduction}

CK2, formerly known as casein kinase II, is ubiquitously distributed in eukaryotes where it was found in a variety of cellular compartments. It phosphorylates more than 300 different proteins which are implicated in the regulation of cell proliferation, differentiation and apoptosis (reviewed in refs. 1-3). High expression of CK2 and an elevated kinase activity was found in many different tumours. CK2 is most often found as a tetrameric complex consisting of two regulatory $\mathrm{CK} 2 \beta$ subunits and two catalytic $\alpha$ and/or $\alpha^{\prime}$ subunits. Knock-out studies of CK $2 \alpha$ or CK $2 \beta$ in mice resulted in embryonic lethality whereas CK2 $\alpha^{\prime}$ knock-out mice are viable but defective in spermatogenesis (4).

CK2 is highly implicated in regulation of cell proliferation and in inhibition of apoptosis $(1,5)$. Thus, many

Correspondence to: Dr Mathias Montenarh, Medizinische Biochemie und Molekularbiologie, Universität des Saarlandes, Gebäude 44, 66424 Homburg, Germany

E-mail: montenarh@uks.eu

Key words: protein kinase CK2, apoptosis, kinase inhibitors, reactive oxygen species, $\gamma-\mathrm{H} 2 \mathrm{AX}$ laboratories attempted to inhibit $\mathrm{CK} 2$ activity in order to inhibit proliferation in particular in cancer cells $(6,7)$. Furthermore, it turned out that inhibition of CK2 also led to apoptosis (7). Thus, CK2 has emerged as a promising pharmacological target for anti-cancer therapy. Consequently different strategies have been employed to inhibit CK2 activity (reviewed in refs. 8-10). Some years ago it was shown that the use of CK2 antisense oligonucleotides resulted in the induction of apoptosis $(5,11)$. In xenograft models of prostate cancer a dose- and time-dependent tumour cell death was induced by the same antisense oligonucleotide (12). Another approach used a kinase inactive CK $2 \alpha-$ K68 A mutant to down-regulate CK2 activity which resulted in a marked inhibition of cell proliferation (13). However, due to variable levels of CK2 in cells efficient down-regulation of the CK2 activity with the inactive $\mathrm{CK} 2 \alpha-\mathrm{K} 68 \mathrm{~A}$ mutant is not suitable. Another strategy to inhibit CK2 activity is provided by RNAi technology $(14,11)$. However, the utilization of this technology is mostly dependent on transfection efficiency and proved to be inefficient, requiring continuous treatment of cells in order to achieve a down-regulation over an appropriate time. Since RNAi technology down-regulates also the level of the protein the altered stoichiometry may disturb regulatory protein-protein interactions. Thus, the search for chemical inhibitors was the most promising strategy for the regulation or inhibition of CK2 activity. Inhibitors can be classified as substrate analogue or nucleotide analogue which can be subdivided into benzimidazole derivatives like tetrabromobenzotriazole, TBB, polyphenole derivatives like emodin, or isochinoline derivatives. Some of the inhibitors like emodin and apigenin have a limited selectivity for CK2. Others like TBB and its derivatives mainly 4,5,6,7-tetrabromobenzimidazole, TBBz or 2-dimethylamino-4,5,6,7-tetrabromo-1H-benzimidazole, DMAT, are selective for CK2 although at least one other kinase, DYRK1a, was also inhibited to some extent (10). The solution of the crystal structure of the complexes between CK2 and TBB (15) and with DMAT (16) led to the conclusion that TBB binds in quite a different manner to CK2 than DMAT. This observation prompted us to analyze whether there are additional variations in the intracellular response after treatment of cells with these two compounds. For this type of study we focused on the hormone-sensitive prostate cancer cell line $\mathrm{LNCaP}$, which is known to go into apoptosis after treatment with the two drugs. We found that 
TBB and DMAT inhibited the CK2 activity to the same extent, however DMAT, in contrast to TBB, induced the formation of reactive oxygen species and DNA double strand breaks. Thus, it is clear from these results that beside its different mode of interaction with CK2 also the intracellular signalling is different.

\section{Materials and methods}

Cell culture and reagents. The hormone-sensitive prostate cancer cell line LNCaP (ATCC CRL-1740) was cultured in RPMI-1640 (Sigma-Aldrich Chemie GmbH, Munich, Germany) supplemented with $10 \%$ fetal bovine serum and $2 \mathrm{mM}$ L-glutamine at $37^{\circ} \mathrm{C}$ in an atmosphere enriched with $5 \% \mathrm{CO}_{2}$. The CK2 inhibitors DMAT and TBB (Sigma-Aldrich Chemie $\mathrm{GmbH}$ ) were dissolved in dimethyl sulfoxide (DMSO) to a $10 \mathrm{mM}$ stock solution which was used to treat the cells in a final concentration of either $30 \mu \mathrm{M}$ for DMAT or $50 \mu \mathrm{M}$ for TBB over a period of 24 and $48 \mathrm{~h}$ (unless otherwise stated). Redox sensitive dye 2',7'-dichlorofluoresceine diacetate $\left(\mathrm{H}_{2} \mathrm{DCFDA}\right)$ was purchased from Molecular Probes B.V. (Leiden, The Netherlands) and also dissolved in DMSO to a stock solution of $100 \mathrm{mM}$.

CK2 in vitro kinase assay. To determine the activity of CK2 after its inhibition cells were treated with TBB or DMAT or left untreated, lysed and the extracts were used in a kinase filter assay. In this assay we measured the incorporation rate of $\left[{ }^{32} \mathrm{P}\right]$-phosphate into the synthetic CK2 specific substrate peptide with the sequence RRRDDDSDDD (17). Twenty $\mu 1$ kinase buffer (50 mM Tris/HCl, pH 7.5, $100 \mathrm{mM} \mathrm{NaCl}, 10 \mathrm{mM}$ $\mathrm{MgCl}_{2}, 1 \mathrm{mM}$ DTT) containing $30 \mu \mathrm{g}$ proteins was mixed with $30 \mu 1 \mathrm{CK} 2 \mathrm{mix}$ (25 mM Tris/HCl, pH 8.5, $150 \mathrm{mM} \mathrm{NaCl}$, $5 \mathrm{mM} \mathrm{MgCl}_{2}, 1 \mathrm{mM}$ DTT, $50 \mu \mathrm{M}$ ATP, $0.19 \mathrm{mM}$ substrate peptide) containing $10 \mu \mathrm{Ci} / 500 \mu 1\left[\gamma^{32} \mathrm{P}\right] \mathrm{ATP}$. The mixture was spotted onto a P81 ion exchange paper. The paper was washed with $85 \mathrm{mM} \mathrm{H}_{3} \mathrm{PO}_{4}$ three times. After treatment with ethanol the paper was dried and the Cerenkov-radiation was determined in a scintillation counter.

Cell viability and proliferation assay. To measure the metabolic activity of the treated cells, we used the MTTassay. In this assay the tetrazolium salt 3-[4,5-dimethylthiazole-2-yl]-2,5-diphenyltetrazoliumbromide (MTT) (SigmaAldrich Chemie $\mathrm{GmbH}$ ) was reduced to a formazane. The day before treatment $2 \times 10^{4}$ cells $/ 500 \mu 1$ were seeded into the wells of a 24-well plate. Cells were treated with the CK2 inhibitors for various time intervals and after the incubation time $50 \mu 1$ of MTT solution ( $5 \mathrm{mg} / \mathrm{ml}$ PBS) was added. After 4 additional hours $500 \mu \mathrm{l}$ of the lysis solution was added and further incubated at $37^{\circ} \mathrm{C}$ till the next morning. The absorption of these lysates was determined at $595 \mathrm{~nm}$ after transferring an aliquot of $200 \mu 1$ into a 96-well plate.

Measurement of intracellular reactive oxygen species. Intracellular concentration of reactive oxygen species was determined by staining the cells with the redox-sensitive dye $\mathrm{H}_{2}$ DCFDA (Molecular Probes B.V.). In the presence of reactive oxygen species $\mathrm{H}_{2}$ DCFDA is oxidized to DCF. The dye detects several kinds of reactive oxygen species namely
$\mathrm{H}_{2} \mathrm{O}_{2}$, $\mathrm{OOH}$ and $\mathrm{NO}^{-}$. Cells were treated with $50 \mu \mathrm{M}$ TBB or $30 \mu \mathrm{M}$ DMAT for 6 and $24 \mathrm{~h}$. Following treatment the cells were washed with PBS, exposed to $5 \mu \mathrm{M} \mathrm{H}_{2}$ DCFDA and incubated at $37^{\circ} \mathrm{C}$ for $30 \mathrm{~min}$. After the incubation cells were washed again in serum-free medium and resuspended in $500 \mu 1$ of the appropriate growth medium. The excitation was measured at $488 \mathrm{~nm}$ and the emission at $525 \mathrm{~nm}$ using a flow cytometer. At least 10,000 counts were analyzed by cell quest software.

Western blot analysis of PARP and its cleavage products and of $\gamma H 2 A X$. Proteins were separated by SDS polyacrylamide gel electrophoresis according to the procedure of Laemmli (18). For Western blot analysis proteins were transferred to a PVDF membrane by tank blotting with $20 \mathrm{mM}$ Tris $/ \mathrm{HCl}$, pH 8.7 and $150 \mathrm{mM}$ glycine as transfer buffer. Membranes were blocked in PBS with $0.1 \%$ Tween-20 and 5\% dry milk for $1 \mathrm{~h}$ at room temperature. The membrane was incubated with the polyclonal PARP antibody (1:1000) (Cell Signaling Technology, Frankfurt, Germany) or with anti $\gamma \mathrm{H} 2 \mathrm{AX}$ antibody pH2AX (1:10000) (Upstate, Schwalbach, Germany) in PBS Tween-20 with $1 \%$ dry milk for another hour. Then the membrane was washed twice for 10 min with PBSTween-20 with $1 \%$ dry milk. Incubation with the peroxidasecoupled secondary antibody (anti-rabbit, 1:30000 anti-mouse 1:10000) followed for $1 \mathrm{~h}$. The membrane was washed again twice for 10 min with PBS-Tween-20. Signals were developed and visualized by the Lumilight system of Roche Diagnostics GmbH (Mannheim, Germany).

\section{Results}

Inhibition of CK2 leads to reduction of cell viability by apoptosis. The development of new inhibitors of protein kinase CK2 has accelerated together with an increase in specificity for CK2. Two of these highly specific inhibitors, TBB and DMAT were investigated for their effect on the hormone sensitive prostate cancer cell line LNCaP. First, an analysis of the inhibitory effect on the CK2 activity was accomplished in a kinase assay by incorporation of $\left[\gamma^{-32} \mathrm{P}\right]-$ phosphate into the synthetic CK2 specific substrate peptide RRRDDDSDDD (19). We applied the inhibitors over a vast range of concentration and ended finally with concentrations of $50 \mu \mathrm{M}$ for TBB or $30 \mu \mathrm{M}$ for DMAT for a period of $48 \mathrm{~h}$. Fig. 1A shows the relative phosphate incorporation into the substrate peptide from control $(100 \%)$ and inhibitor treated cells. We found that using this particular concentration of inhibitors there is no gross difference in inhibition of the CK2 kinase activity with TBB in comparison to DMAT.

Having shown that both TBB and DMAT inhibited CK2 activity to nearly the same extent we analyzed the viability of the cells after treatment with the inhibitors. The metabolic activity of the cells especially the enzymatic activity of the mitochondrial dehydrogenases was measured with an MTT assay. The viability of the TBB or DMAT treated cells was compared to control treated cells. According to Fig. 1B the viability of cells was reduced by both inhibitors. However, DMAT led to a stronger reduction in the number of viable cells than TBB. With TBB we found a reduction of only $20 \%$ whereas the reduction with DMAT is about $40 \%$ after $24 \mathrm{~h}$. 
A

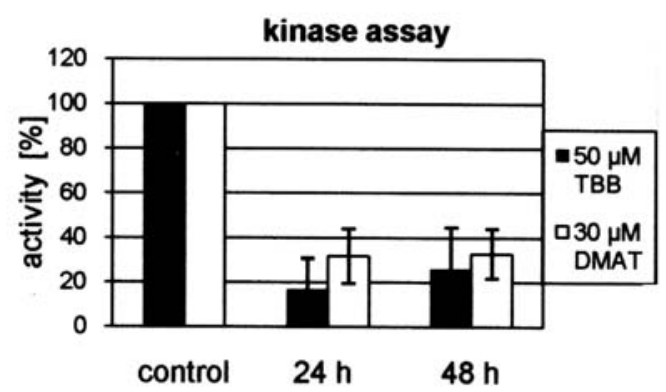

B

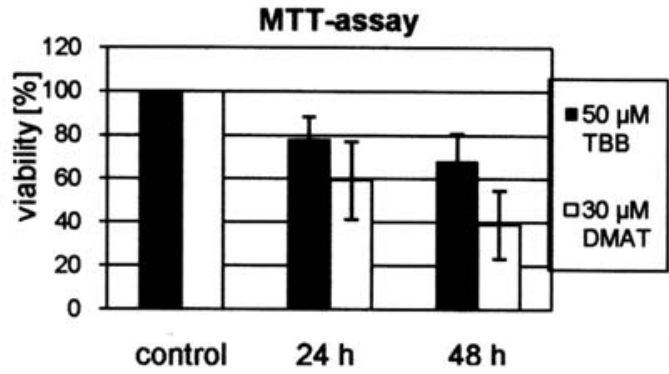

Figure 1. Protein kinase CK2 activity and viability of LNCaP cells after treatment with TBB or DMAT. (A) CK2 activity was measured in extracts from cells treated with 0 and $50 \mu \mathrm{M}$ TBB or $30 \mu \mathrm{M}$ DMAT for 24 and $48 \mathrm{~h}$ by the incorporation of $\left[{ }^{32} \mathrm{P}\right]$-phosphate into a synthetic substrate. (B) Cells $\left(2 \times 10^{4}\right)$ were seeded in a 24 -well tissue culture plate. Growth of mock treated $(0 \mu \mathrm{M})$ and $50 \mu \mathrm{M}$ TBB or $30 \mu \mathrm{M}$ DMAT treated cells was measured after 24 and $48 \mathrm{~h}$ by the MTT assay.

This reduction in viability was even more pronounced when the cells were treated for $48 \mathrm{~h}$. The decrease in the viability of cells could either be due to a cell cycle arrest or to cell death by apoptosis. In order to analyze apoptosis we determined the cleavage of PARP which is a late event in apoptosis. Full length PARP and its cleavage product were analyzed with an antibody which recognizes full length PARP with a molecular weight of $116 \mathrm{kDa}$ and its cleavage product of $85-90 \mathrm{kDa}$. As shown in Fig. 2 cleavage of PARP occurred after treatment with both CK2 inhibitors. Taking all three results together it can be assessed that the inhibition of CK2 by either TBB or DMAT leads to a reduction in cell viability due to apoptosis.

$T B B$ and DMAT differ in the mode of intracellular response. Reactive oxygen species are emerging as critical signaling molecules (20). The term reactive oxygen species (ROS) encompasses a wide range of molecules such as $\mathrm{O}_{2}{ }^{-}$, hydrogen peroxide $\left(\mathrm{H}_{2} \mathrm{O}_{2}\right)$, hydroxyl radical and peroxynitrite. It has been shown that mitochondrial ROS production triggers apoptosis (21) and therefore we investigated whether reactive oxygen species (ROS) might play a role in the cellular response to TBB or DMAT treatment of cells. To determine reactive oxygen species the fluorescent dye $\mathrm{H}_{2}$ DCFDA was used. In the presence of ROS $\mathrm{H}_{2}$ DCFDA is oxidized to DCF. This dye is able to detect the following reactive oxygen species $\mathrm{H}_{2} \mathrm{O}_{2}$, ${ }^{\circ} \mathrm{OOH}$ and $\mathrm{NO}_{3}{ }^{-}$. Cells were treated with $50 \mu \mathrm{M}$ TBB and $30 \mu \mathrm{M}$ DMAT over a period of 6 and 24 h. Cells were analyzed in a flow cytometer to detect the reactive

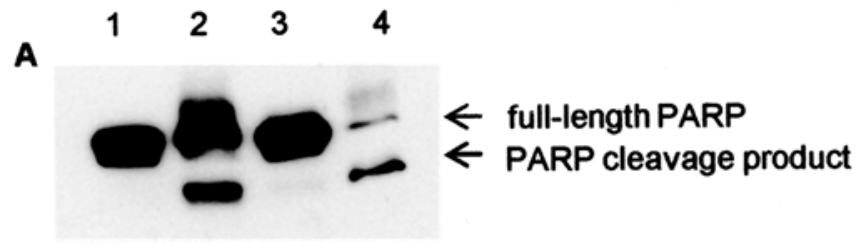

$\mathbf{B}$

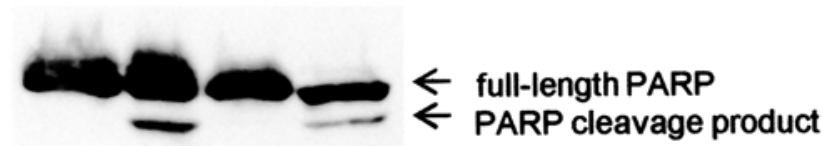

Figure 2. PARP cleavage in cells treated with TBB or DMAT. Proteins $(150 \mu \mathrm{g})$ of TBB or DMAT treated LNCaP cell extracts were separated by electrophoresis through a $10 \%$ SDS-polyacrylamide gel and transferred onto a PVDF membrane. PARP-fragments were detected with a PARP-specific antibody. Lanes 1 and 2, treatment for $24 \mathrm{~h}$ with 0 and $50 \mu \mathrm{M}$ TBB (panel A) or 0 and $30 \mu \mathrm{M}$ DMAT (panel B); lanes 3 and 4 , treatment for $48 \mathrm{~h}$ with 0 and $50 \mu \mathrm{M}$ TBB (A) or 0 and $30 \mu \mathrm{M}$ DMAT (B).

oxygen species. In Fig. 3 it is demonstrated that after TBB treatment we were unable to detect ROS. However, in the case of DMAT treatment we observed reactive oxygen species after $6 \mathrm{~h}$ as well as after $24 \mathrm{~h}$ of treatment.

Increased ROS can induce genomic instability leading to DNA double strand breaks (DSBs) (22). Thus, we decided to analyze whether DMAT might induce DSBs. The phosphorylation of the histone variant $\mathrm{H} 2 \mathrm{AX}$ at serine 139 , a form called $\gamma \mathrm{H} 2 \mathrm{AX}$, has been characterized as a very early event following induction of DSBs. Therefore, we analyzed $\gamma \mathrm{H} 2 \mathrm{AX}$ formation after treatment of cells with TBB or with DMAT in comparison to untreated cells by Western blotting. Cells were treated for 4 and $24 \mathrm{~h}$ with $\mathrm{TBB}(50 \mu \mathrm{M})$ and DMAT $(30 \mu \mathrm{M})$, cells were extracted and the cell extract analyzed by SDS-polyacrylamide gel electrophoresis followed by Western blotting with an antibody specific for phosphorylated H2AX. As shown in Fig. 4 there was a considerable increase in the amount of $\gamma-\mathrm{H} 2 \mathrm{AX}$ after treatment with DMAT whereas there was only a slight increase after TBB treatment.

The detection of reactive oxygen species and the following DSBs strongly indicate that in addition to the inhibition of CK2 DMAT induces reactive oxygen species and DNA double strand breaks whereas TBB only inhibited CK2 activity without inducing ROS.

\section{Discussion}

Targeting protein kinase CK2 for potential therapeutic applications has become a rapidly evolving field. A number of different strategies for inhibition of CK2 activity were used. It turned out that both 4,5,6,7-tetrabromo-1,4benzotriazol (TBB) and 2-dimethylamino-4,5,6,7-tetrabromo-1H-benzimidazol (DMAT) exhibit a high specificity for protein kinase CK2 although, at least the dual specificity tyrosine phosphorylation-regulated kinase 1a (DYRK1a) is also inhibited by both inhibitors (10). Both, TBB and DMAT belong to the class of ATP-competitive inhibitors of CK2 and thus, one would expect that both inhibitors might have a low specificity. However, unique features surrounding the ATP 

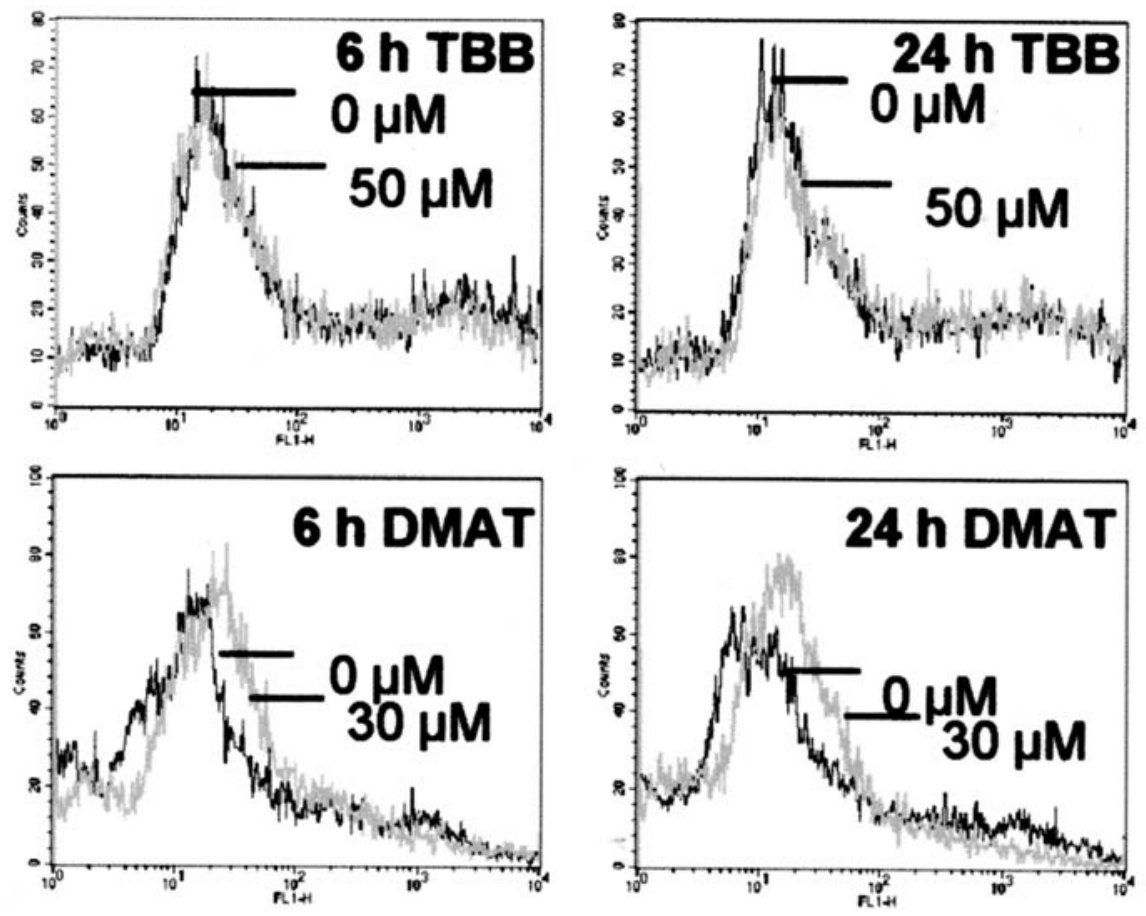

Figure 3. Measurement of reactive oxygen species (ROS) after CK2-inhibition in LNCaP prostate cancer cells. LNCaP cells were incubated with $50 \mu \mathrm{M}$ TBB or $30 \mu \mathrm{M}$ DMAT for 6 and $24 \mathrm{~h}$ to detect an increase in ROS production using the fluorescent dye $\mathrm{H}_{2} \mathrm{DCFDA}$. At least 10,000 counts were recorded by flow cytometry.

pocket and in particular a reduced size of the ATP pocket is responsible for the high specificity of TBB because TBB perfectly fits into this pocket. DMAT seems to contact the ATP pocket and its environment in a somewhat different fashion as deduced from mutation analysis of residues close to the ATP pocket (16).

Here, we show that in prostate cancer cells $\mathrm{TBB}$ and DMAT led to an inhibition of the CK2 activity to nearly the same extent. Viability of cells treated with DMAT is more reduced than viability of cells treated with TBB. Furthermore, treatment with both inhibitors resulted in apoptosis of the prostate cancer cells which is in agreement with earlier observations (11). However, recently there was some indication that TBB and DMAT might exert unique biological properties (8) which is strongly supported by the present study showing that DMAT led to the induction of reactive oxygen species (ROS) whereas TBB did not induce ROS.

Induction of ROS is accompanied by the formation of DNA double strand breaks which were detected by the determination of the level of phosphorylated H2AX (23). ROS-mediated DNA damage has long been thought to play a role in the initiation of carcinogenesis and in malignant transformation (24). ROS react with pyrimidines and purins of DNA resulting in base modifications, genomic instability and an altered gene expression. However, there is a growing body of data that the mitogenic signal of ROS is only observed at low ROS levels. Furthermore, a significant growth stimulation occurs when DU145 prostate cancer cells were exposed to $\mathrm{H}_{2} \mathrm{O}_{2}(25)$. On the other hand exposure of androgendependent LNCaP or androgen independent PC-3 or DU145 prostate cancer cells to prostate specific antigen increased $\mathrm{H}_{2} \mathrm{O}_{2}$ levels (26). High levels of ROS can cause apoptosis by triggering mitochondrial permeability and release of pro-

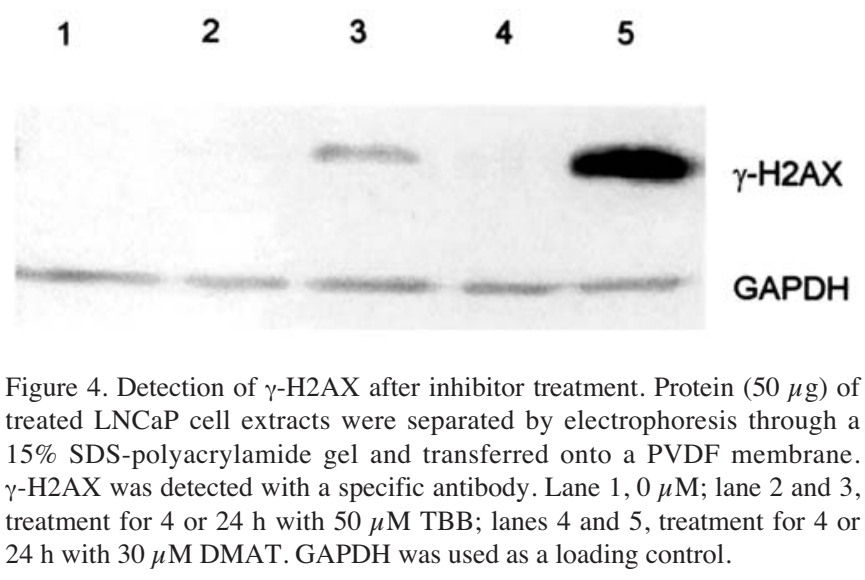

apoptotic factors (21). This is the reason why a failure in the antioxidant system in cells leads to DNA-damage and apoptosis. Moreover, the DNA repair pathways are coupled with apoptosis effectors to ensure that irreparable DNA damage will not be passed to daughter cells. There was already a report showing $\mathrm{H}_{2} \mathrm{O}_{2}$ production in prostate cancer cells after down-regulation of the level of CK2 by antisense CK2 $\alpha$, or by small interfering CK2 $\alpha$ RNA or by inhibition of CK2 activity. Using high concentrations of TBB Ahmed et al (27) detected ROS in androgen-dependent ALVA-41 and androgenindependent PC-3 cells. Using the same high concentration of TBB we did not detect ROS (data not shown). The reason for this discrepancy is not clear but might be due to the different cell lines used for these studies. Since in our hands TBB treated cells never resulted in the formation of ROS and only low levels of DSBs, if at all, were detected, we conclude from these results that ROS formation is not a prerequisite 
for apoptosis induction. Our present results show that two closely related molecules such as TBB and DMAT induce different signalling pathways in the cell. Thus, before using these kinase inhibitors in cancer therapy one has to control for toxic side effects.

\section{Acknowledgements}

This study was supported by Homfor 06/28 to C.G.

\section{References}

1. Litchfield DW: Protein kinase CK2: structure, regulation and role in cellular decisions of life and death. Biochem J 369: 1-15, 2003.

2. Pinna LA and Meggio F: Protein kinase CK2 ('casein kinase-2') and its implication in cell division and proliferation. Prog Cell Cycle Res 3: 77-97, 1997

3. Guerra B and Issinger OG: Protein kinase CK2 and its role in cellular proliferation, development and pathology. Electrophoresis 20: 391-408, 1999 .

4. Xu X, Toselli PA, Russell LD and Seldin DC: Globozoospermia in mice lacking the casein kinase II $\alpha^{\prime}$ catalytic subunit. Nat Genet 23: $118-121,1999$.

5. Unger GM, Davis AT, Slaton JW and Ahmed K: Protein kinase CK2 as regulator of cell survival: implications for cancer therapy. Curr Cancer Drug Targets 4: 77-84, 2004.

6. Duncan JS and Litchfield DW: Too much of a good thing: the role of protein kinase CK2 in tumorigenesis and prospects for therapeutic inhibition of CK2. Biochim Biophys Acta 1784: $33-47,2008$

7. Zien P, Duncan JS, Skierski J, Bretner M, Litchfield DW and Shugar D: Tetrabromobenzotriazole (TBBt) and tetrabromobenzimidazole $(\mathrm{TBBz})$ as selective inhibitors of protein kinase CK2: evaluation of their effects on cells and different molecular forms of human CK2. Biochim Biophys Acta 1754: 271-280, 2005.

8. Duncan JS, Gyenis L, Lenehan J, Bretner M, Graves LM, Haystead TA and Litchfield DW: An unbiased evaluation of CK2 inhibitors by chemoproteomics: characterization of inhibitor effects on CK2 and identification of novel inhibitor targets. Mol Cell Proteomics 7: 1077-1088, 2008.

9. Prudent R, Moucadel V, Lopez-Ramos M, Aci S, Laudet B, Mouawad L, Barette C, Einhorn J, Einhorn C, Denis JN, Bisson G, Schmidt F, Roy S, Lafanechere L, Florent JC and Cochet C: Expanding the chemical diversity of CK2 inhibitors. Mol Cell Biochem 316: 71-85, 2008.

10. Pagano MA, Bain J, Kazimierczuk Z, Sarno S, Ruzzene M, Di Maira G, Elliott M, Orzeszko A, Cozza G, Meggio F and Pinna LA: The selectivity of inhibitors of protein kinase CK2. An update. Biochem J 415: 353-365, 2008.

11. Wang G, Unger G, Ahmad KA, Slaton JW and Ahmed K Downregulation of CK2 induces apoptosis in cancer cells-a potential approach to cancer therapy. Mol Cell Biochem 274: $77-84,2005$
12. Slaton JW, Unger GM, Sloper DT, Davis AT and Ahmed K: Induction of apoptosis by antisense CK2 in human prostate cancer xenograft model. Cell Growth Differ 2: 712-721, 2004.

13. Lebrin F, Chambaz EM and Bianchini L: A role for protein kinase CK2 in cell proliferation: evidence using a kinaseinactive mutant of CK2 catalytic subunit $\alpha$. Oncogene 20: 2010-2022, 2001.

14. Hamacher R, Saur D, Fritsch R, Reichert M, Schmid RM and Schneider G: Casein kinase II inhibition induces apoptosis in pancreatic cancer cells. Oncol Rep 18: 695-701, 2007.

15. Battistutta R, De Moliner E, Sarno S, Zanotti G and Pinna LA: Structural features underlying selective inhibition of protein kinase CK2 by ATP site-directed tetrabromo-2-benzotriazole. Protein Sci 10: 2200-2206, 2001.

16. Battistutta R, Mazzorana M, Sarno S, Kazimierczuk Z, Zanotti G and Pinna LA: Inspecting the structure-activity relationship of protein kinase CK2 inhibitors derived from tetrabromobenzimidazole. Chem Biol 12: 1211-1219, 2005.

17. Kuenzel EA, Mulligan JA, Sommercorn J and Krebs EG: Substrat specificity determinants for casein kinase II as deduced from studies with synthetic peptides. J Biol Chem 262: 9136-9140, 1987.

18. Laemmli UK: Cleavage of structural proteins during the assembly of the head of bacteriophage T 4. Nature 227: 680-682, 1970.

19. Kuenzel EA and Krebs EG: A synthetic peptide substrate specific for casein kinase II. Proc Natl Acad Sci USA 82: 737-741, 1985.

20. Ueda S, Masutani H, Nakamura H, Tanaka T, Ueno M and Yodoi J: Redox control of cell death. Antioxid Redox Signal 4: 405-414, 2002

21. Le Bras M, Clement MV, Pervaiz S and Brenner C: Reactive oxygen species and the mitochondrial signaling pathway of cell death. Histol Histopathol 20: 205-219, 2005.

22. Sallmyr A, Fan J and Rassool FV: Genomic instability in myeloid malignancies: increased reactive oxygen species (ROS), DNA double strand breaks (DSBs) and error-prone repair. Cancer Lett 270: 1-9, 2008.

23. Lowndes NF and Toh GWL: DNA repair: the importance of phosphorylating histone H2AX. Curr Biol 15: R99-R102, 2005.

24. Valko M, Rhodes CJ, Moncol J, Izakovic M and Mazur M: Free radicals, metals and antioxidants in oxidative stress-induced cancer. Chem Biol Interact 160: 1-40, 2006.

25. Sauer H, Diedershagen H, Hescheler J and Wartenberg M: Calcium-dependence of hydrogen peroxide-induced c-fos expression and growth stimulation of multicellular prostate tumor spheroids. FEBS Lett 419: 201-205, 1997.

26. Sun XY, Donald SP and Phang JM: Testosterone and prostate specific antigen stimulate generation of reactive oxygen species in prostate cancer cells. Carcinogenesis 22: 1775-1780, 2001.

27. Ahmad KA, Wang G and Ahmed K: Intracellular hydrogen peroxide production is an upstream event in apoptosis induced by down-regulation of casein kinase 2 in prostate cancer cells. Mol Cancer Res 4: 331-338, 2006. 